\title{
AN AUTOMATIC WAVE PROBE REFERENCE SETTING MECHANISM IN A HIGH SPEED TOWING TANK
}

\author{
A.Adithya Kashyap ${ }^{1}$, B.Prasad $\operatorname{Rao}^{2}$, Y.Srinivasa $\operatorname{Rao}^{3}$, K.Srinivasa $\operatorname{Rao}^{4}$ \\ ${ }^{1}$ Assistant Professor, Dept of EIE, VNRVJIET, Hyderabad, India. \\ ${ }^{2}$ Research Scholar, ${ }^{3 \& 4}$ Professor, Dept of Instrument Technology, AU College of Engineering, Vishakhapatnam, India \\ kashyapadithya@yahoo.co.in
}

\begin{abstract}
The wave generation system in a High Speed Towing Tank (HSTT) generates regular and irregular waves to simulate wave condition during ship model testing. A wave probe is used to measure the height of waves generated by the wave generation system which is placed at the centre of the towing tank from the wave generation system. Generally the initial wave height reference (zero-point) at no wave condition is set manually and it is difficult to set reference accurately and the procedure is time consuming. The work aims at development of an automatic mechanism for adjustment of zero point in HSTT. The intended system enables remote monitoring and setting wave probe height reference with better accuracy minimizing human intervention. The prototype results confirmed the efficacy of the proposed mechanism.
\end{abstract}

Keywords: Towing Tank, Wave probe, Wave generating system.

\section{INTRODUCTION}

The High Speed Towing Tank (HSTT) is a test facility for carrying out model testing under various conditions including simulated sea conditions for determining the performance of the surface and submerged bodies and evaluation of their hydrodynamic characteristics.

The dimensions of HSTT is considered as $500 \mathrm{~m} \times 8 \mathrm{~m} \times 8 \mathrm{~m}$ $(\mathrm{LxBxD})$. The facility has a high speed towing carriage which runs on parallel rails upto a maximum speed of $20 \mathrm{~m} / \mathrm{sec}$ with an accuracy of $0.1 \%$ of set speed. HSTT features a dual flap type wave generator capable of generating regular and irregular waves (unidirectional) up to wave height of $0.5 \mathrm{~m}$.

The waves generated by the wave generation system are measured using a conductive type wave gauge (wave probe). The wave probe is placed at the centre of the towing tank $20 \mathrm{~m}$ from the wave generation system.

At present the initial wave height reference (zero-point) at no wave condition is set manually, i.e. a person goes into the tank and fixes the probe to the reference point at the no wave condition. It is difficult to set the reference accurately and the procedure is time consuming. Thus a mechanism for remote monitoring with a provision for adjustment of the reference point ('zero') in an HSTT is highly desired.

\section{METHODOLOGY}

\subsection{BLOCK DIAGRAM}

The mechanism used in the system for setting the wave probe reference consists of two sections; Transmitter section and the Receiver section.

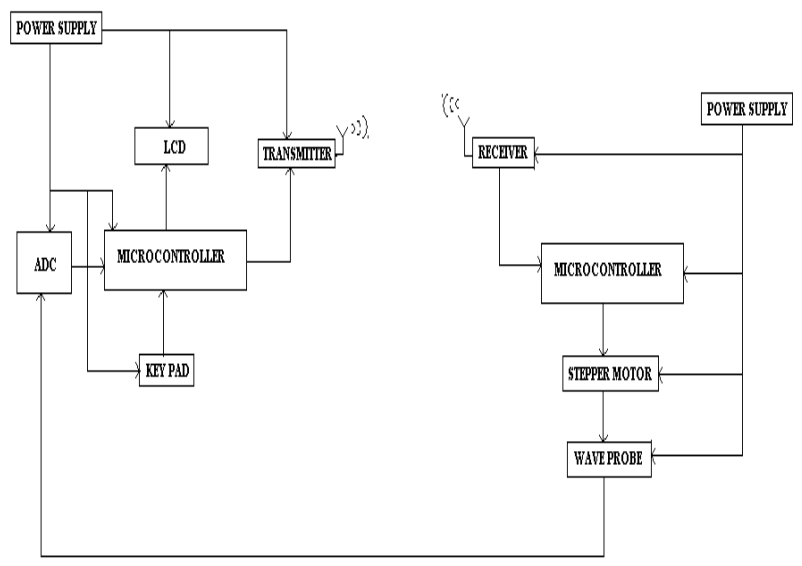

Fig 1: Block diagram of the proposed mechanism

As shown in the block diagram of the system in Fig 1, there are two microcontroller units. First unit is used to display the position of wave probe and transmit the control signal to the other microcontroller unit. The second microcontroller unit is 
used to set the position of wave probe according to the received control signal.

Waves are generated by wave generation system and are measured using a wave probe which gives voltage in the range of $+/-10 \mathrm{~V}$ according to the wave level. This voltage is feed to the ADC through a cable. The microcontroller receives the digital output of the ADC. According to the digital data the microcontroller displays the position $(\mathrm{cm})$ and the output voltage $(\mathrm{V})$ of the wave probe which is presented on the LCD display. If the wave probe is not at the 'zero' reference position, the microcontroller displays other than 'zero' value To bring the wave probe position at 'zero' reference point we use a keypad by which a control signal is sent to other microcontroller unit through the transmitter.

At the other microcontroller unit the receiver receives the control signal and feeds the microcontroller. According to the control signal, the microcontroller drives the stepper motor in forward or reverse direction. The wave probe is mechanically attached to the stepper motor. Therefore when the stepper motor rotates the wave probe moves upward or downward direction till the position at the 'zero' reference point.

\subsection{CIRCUIT DETAILS}

As shown in the circuit in Fig 2 the $50 \Omega$ metal resister attached between REFOUT and REFIN, is used to operate in unipolar mode (i.e. 0 to $+10 \mathrm{~V}$ and 0 to $+20 \mathrm{~V}$ ). In this case the BIPOFF is connected to the ground. If the BIPOFF is connected as shown in the circuit, the ADC operates bipolar input (i.e. $+/-10 \mathrm{~V}$ and $+/-5 \mathrm{~V}$ ).

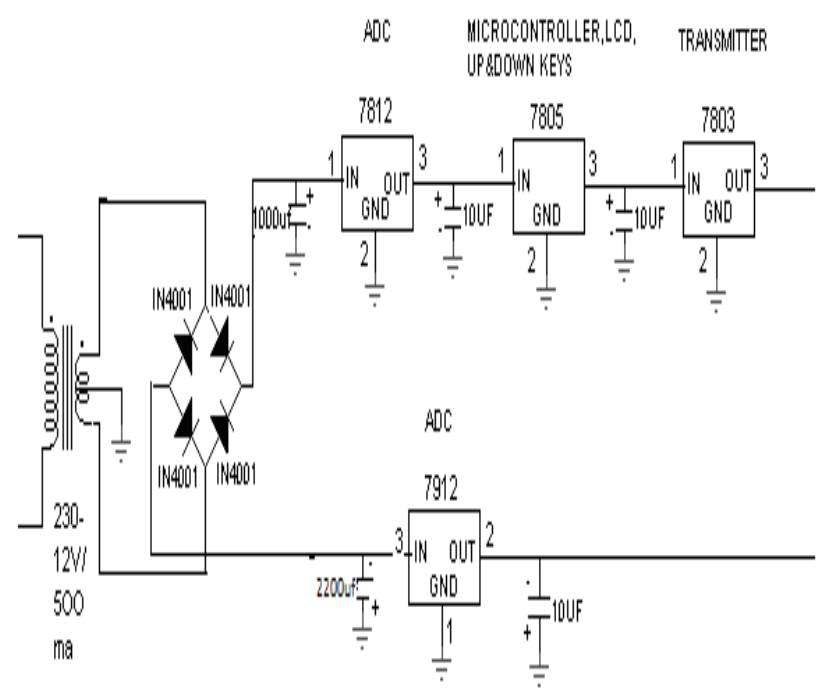

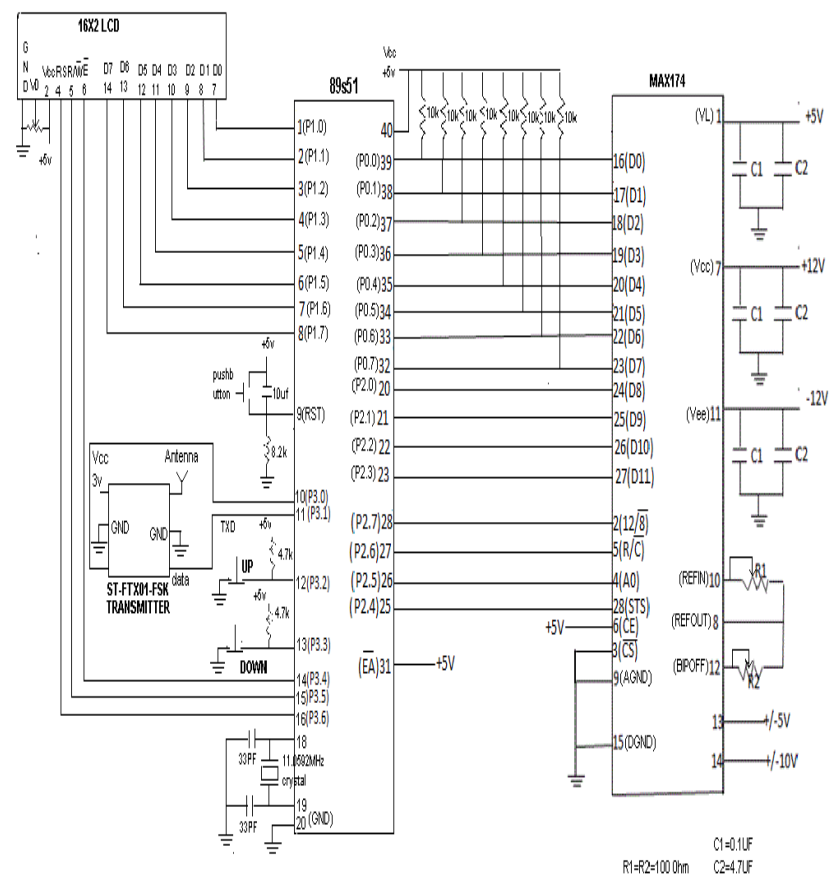

Figure 2

Now the analog signal should be converted into the digital data and the MAX174 ADC uses a successive approximation technique to convert unknown analog input to a 12-bit digital output code according to the control signal as shown in the truth table.

Table 1: Truth Table

\begin{tabular}{|l|l|l|l|l|l|}
\hline CE & CS & R/C & $12 / 8$ & A0 & \multicolumn{2}{|l|}{ OPERATION } \\
\hline 1 & 0 & 0 & $\mathrm{X}$ & 0 & $\begin{array}{l}\text { Initial 12-bit } \\
\text { conversion }\end{array}$ \\
\hline 1 & 0 & 0 & $\mathrm{X}$ & 1 & $\begin{array}{l}\text { Initial 8-bit } \\
\text { conversion }\end{array}$ \\
\hline 1 & 0 & 1 & 0 & $\mathrm{X}$ & $\begin{array}{l}\text { Enable 12-bit } \\
\text { parallel output }\end{array}$ \\
\hline 1 & 0 & 1 & 1 & 0 & $\begin{array}{l}\text { Enable 8-bit } \\
\text { MSB parallel } \\
\text { output }\end{array}$ \\
\hline
\end{tabular}

The output of the ADC signal also depends upon the control signal as shown in the truth table. These control signals are connected to the higher nibble of port- 2 of the microcontroller. The digital outputs of the ADC pins are connected to port- 0 and to the lower nibble of the port- 2 of microcontroller. The microcontroller receives the digital data and accordingly displays the position and the output voltage of wave probe on LCD. The LCD data pins are connected to the port-1 and the 
control signal pins of LCD are connected to the some of the port-3 of controller.

For the LCD display other than 'zero' reference value we use normally on-off-on switch which is connected to external interrupts of the micro controller. When these push buttons are used some controlling message will pass through the serial TxD pin to the ST-FTX01-FSK transmitter module. The controlling message takes FSK modulation with $434 / 868 \mathrm{MHz}$ frequency range. This modulated signal takes the transmitter.

The receiver receives the $434 / 868 \mathrm{MHz}$ range of frequency signals and demodulates the digital data. The data is given to the microcontroller through serial $\mathrm{RxD}$ pin. Now the microcontroller compares the controlling message by using a program. According to that data it drives the stepper motor in forward or reverse direction. But the microcontroller cannot drive the stepper motor because it does not give sufficient current to the motor. IRI44N power MOSFET is used like a driver to drive the stepper motor
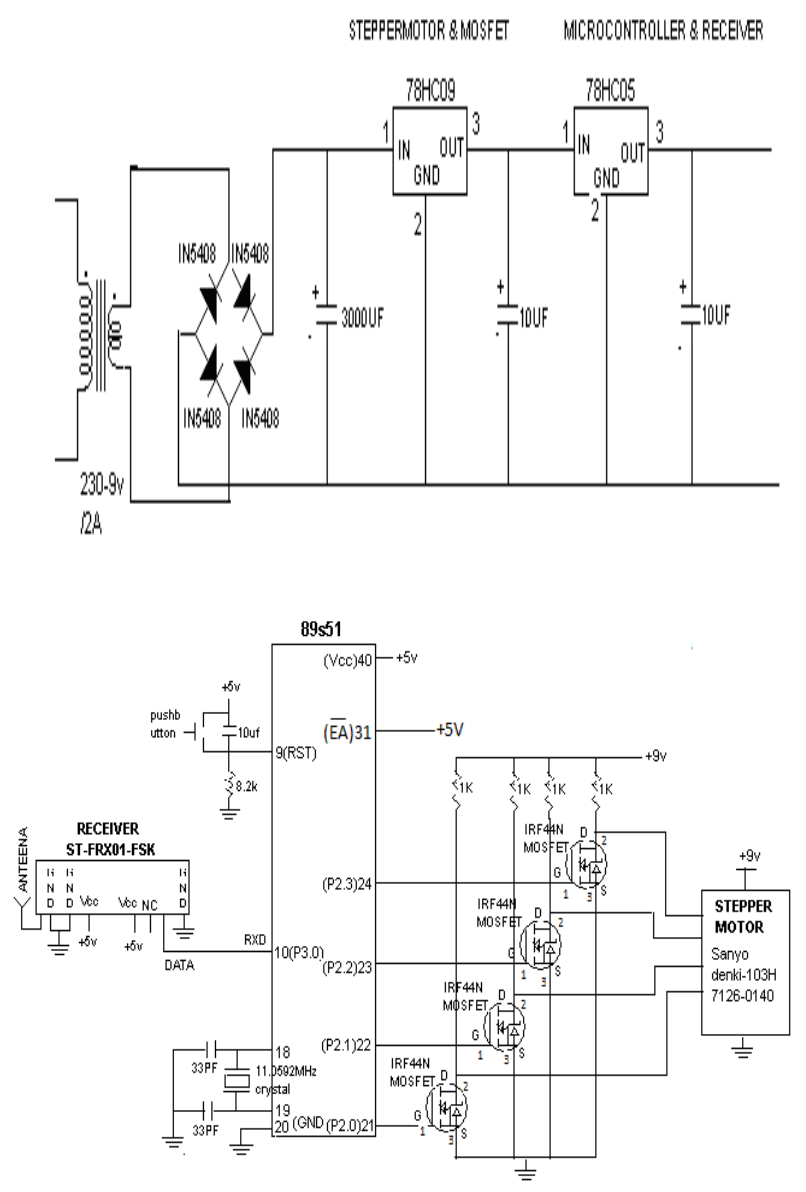

Figure 3
Each MOSFET is connected to microcontroller and stepper motor as shown in the Figure 3.

The systems in Figure 2 and Figure 3 require individual power supply. In the power supply unit we use step down transformer to get the required voltage from the $230 \mathrm{~V}$ AC input. This voltage is converted into DC voltage by using rectifiers (diodes like IN4007 and IN5409). The output of the rectifiers consist some amount of the ripples and to filter the AC ripples we use a smoothing capacitor. This DC voltage is regulated by the regulators according to the application.

The stepper motor is allowed to the wave probe with mechanical interface as shown in Figure 4.

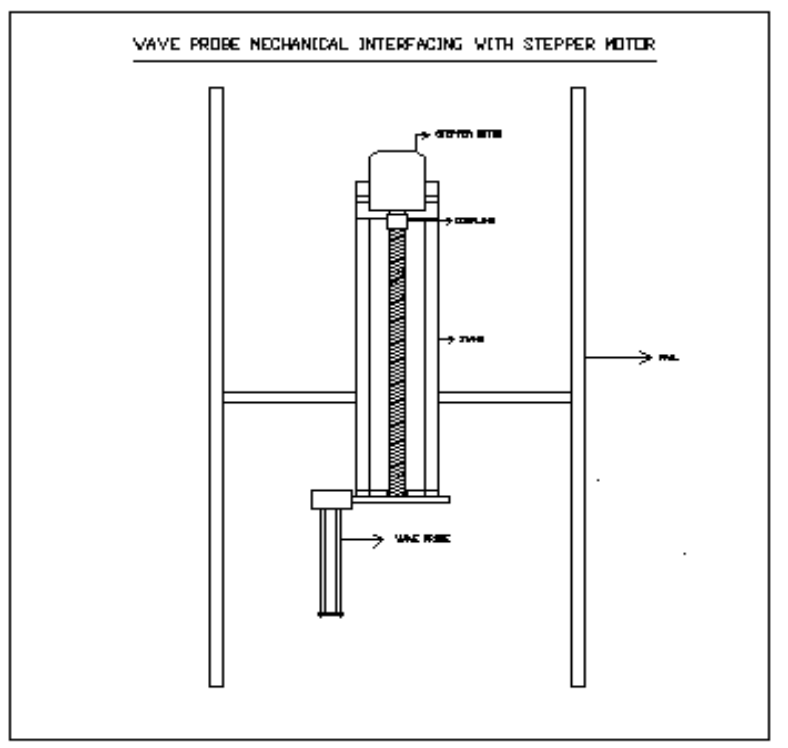

Figure 4

The wave probe is based on a conductivity type wave gauge which comprises two thin parallel stainless steel electrodes. When immersed in water, the meter measures the conductivity of the water volume between the two electrodes that changes proportionally with the change in water surface elevation, i.e. the wave height between electrodes.

\section{FLOWCHART:}

The wave probe reference setting is controlled by the microcontroller software. The embedded software development is carried out with the keil vision3IDE (Integrated Development Environment). By using the software we select conversion and read mode as shown in Figure 5.

After the completion of the conversion the reading data is kept in two registers since the reading data is of 12-bit size. This 12-bit data should be converted into 8-bit data by using embedded software since the LCD used can receive and display 8-bit data only at a time. 
The LCD control signals are also controlled by the microcontroller software. When the program is executed it checks the interrupts every time. If any interrupt takes place then it will send data i.e. controlling data to the other microcontroller through serial communication.

Here the serial communication takes place with 9600 baud rate and this baud rate can also be changed by using the program. Now the received data in other microcontroller compares. If this data equals to the reference data the microcontroller software rotates the stepper motor in the direction of reverse or forward according to the data. Otherwise the microcontroller will wait till the required data received.

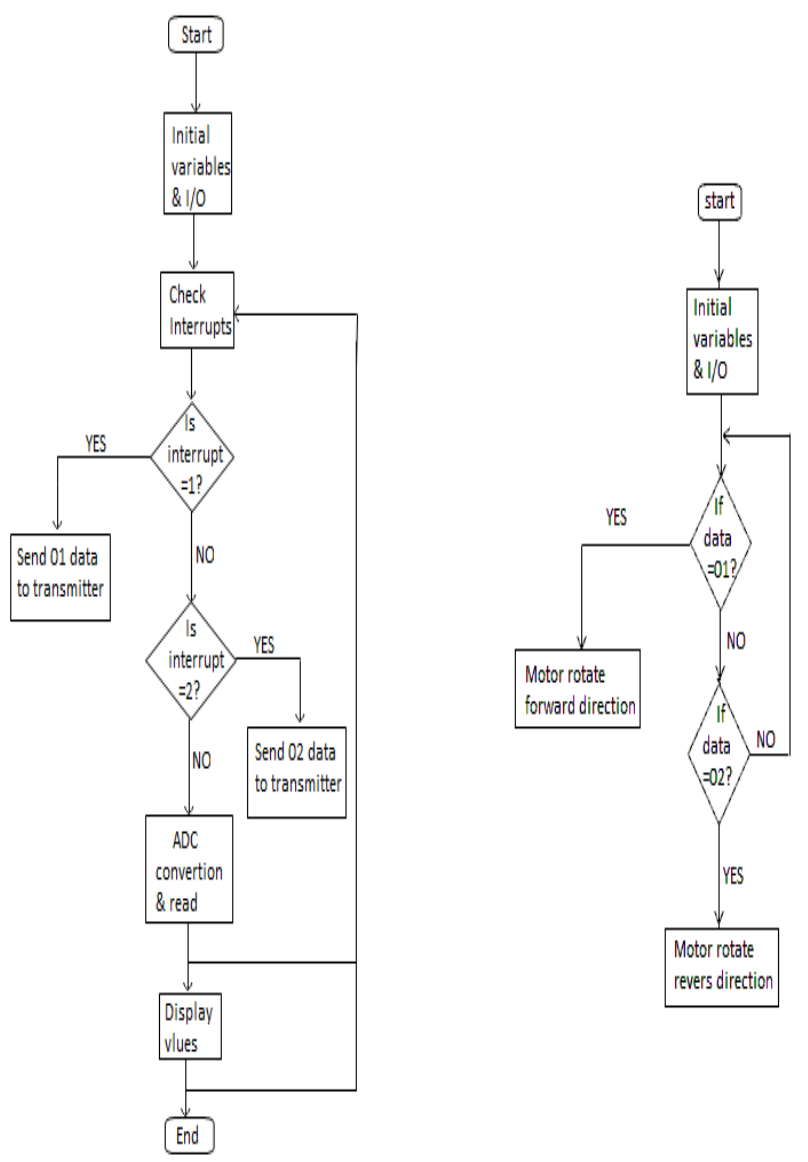

Figure 5 - Flowchart

\section{RESULTS AND ANALYSIS:}

The hardware and software test is done thoroughly and the bench test is done. The output of the wave probe and the length of probe manual are compared with multi meter \& vernier scale and are listed in Table 2.
Table 2

\begin{tabular}{|l|l|l|l|}
\hline \multicolumn{2}{|c|}{$\begin{array}{l}\text { WAVE PROBE } \\
\text { POSITION }(\mathrm{cm})\end{array}$} & $\begin{array}{l}\text { WAVE } \\
\text { OUTPUT } \\
(\text { V) }\end{array}$ & $\begin{array}{l}\text { PROBE } \\
\text { VOLTAGE }\end{array}$ \\
\hline $\begin{array}{l}\text { Scale } \\
\text { readings } \\
(\mathrm{cm})\end{array}$ & $\begin{array}{l}\text { System } \\
\text { readings } \\
(\mathrm{cm})\end{array}$ & $\begin{array}{l}\text { Multi } \\
\text { Meter } \\
\text { readings } \\
(\mathrm{V})\end{array}$ & $\begin{array}{l}\text { System } \\
\text { readings } \\
(\mathrm{V})\end{array}$ \\
\hline 0 & 0.009 & -0.004 & 0.014 \\
\hline 0.6 & 0.504 & 0.129 & 0.136 \\
\hline 1.1 & 1.011 & 0.278 & 0.283 \\
\hline 2.2 & 2.005 & 0.555 & 0.561 \\
\hline 3.2 & 3.016 & 0.833 & 0.844 \\
\hline 5.3 & 5.075 & 1.393 & 1.406 \\
\hline 10.3 & 10.069 & 2.786 & 2.797 \\
\hline
\end{tabular}

The error profile plots shown in Fig 6 which are measured from the difference between the system readings and manually measured readings are obtained.

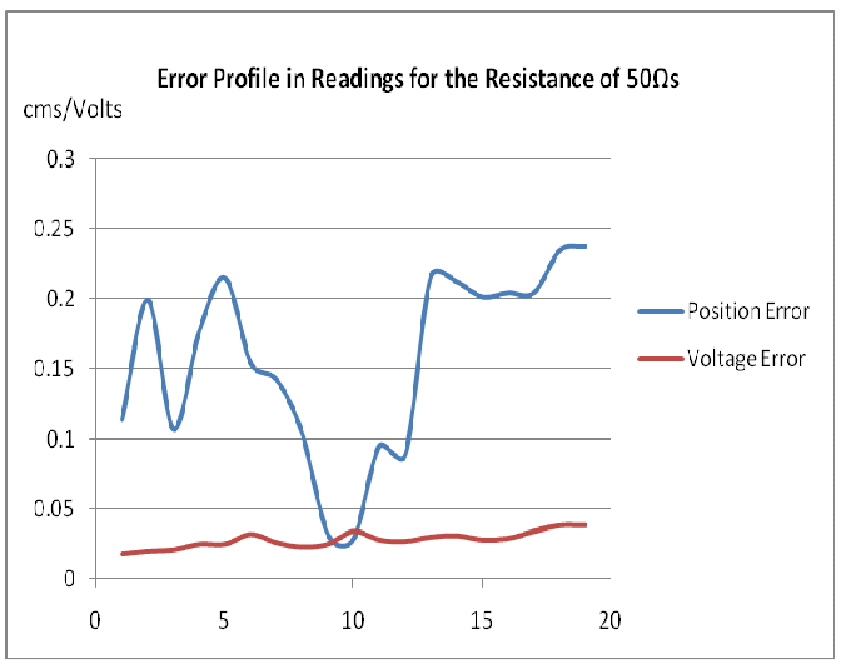

Figure 6 - Error Profile plots

The mechanical arrangement and the environmental conditions result in slight change in the measured values from the expected result, so the expected output is not exactly same as the system reading. The significance of these plots is that, it indicates the variation of the error value for different instances.

\section{CONCLUSIONS}

An automatic mechanism for remote monitoring with a provision for adjustment of reference point ('ZERO') in a HSTT was proposed. There is an observed increase in performance with the designed system and this system adjusted the wave probe at the reference point ('zero') remotely. The system can be programmed to work in 
automatic mode by making changes in the program where the system checks the reference value and if there is no reference value automatically it comes to reference value.

\section{REFERENCES}

[1] J.Tukker, J.J.Blok, G.Kulper, R.H.M.Huijsmans, "Wake flow measurements in Towing Tanks with PIV" at 9th International symposium on Flow visualization 2000.

[2] Johnson, B. and S. Enzinger, "Inexpensive Side Beaches for Improving Calm Water Testing Efficiency", Proceedings of the 18th International Towing Tank Conference, 1987.

[3] Jeng Horng Chen, Che-Chun Chang, "A moving PIV system for ship model test in a Towing tank", Science Direct, 2006

[4] Gregory Payne, "Guidance for the experimental tank testing of wave energy converters", Supergenmarine, University of Edinburgh

[5] J.M.J. Journée and Jakob Pinkster "Introduction to Ship hydromechanics" Draft Edition, April 2002

[6] A Maggi, G Thomas and B McRae "A comparision of Numerical and Towing Tank predictions with full scale measurement” RINA International Conference, 1998. 